\title{
Total Static Balancing and Kinetostatics of the 3R Base Cinematic Chain
}

\author{
${ }^{1}$ Relly Victoria Petrescu, ${ }^{2}$ Raffaella Aversa, \\ ${ }^{2}$ Antonio Apicella and ${ }^{1}$ Florian Ion Tiberiu Petrescu \\ ${ }^{1}$ ARoTMM-IFToMM, Bucharest Polytechnic University, Bucharest, (CE), Romania \\ ${ }^{2}$ Advanced Material Lab, Department of Architecture and Industrial Design, \\ Second University of Naples, 81031 Aversa (CE), Italy
}

\author{
Article history \\ Received: 12-01-2018 \\ Revised: 13-01-2018 \\ Accepted: 17-01-2018 \\ Corresponding Author: \\ Florian Ion Tiberiu Petrescu \\ ARoTMM-IFToMM, Bucharest \\ Polytechnic University, \\ Bucharest, (CE), Romania \\ E-mail: scipub02@gmail.com
}

\begin{abstract}
It has been presented in other works and studied matrix spatially, or more simply in a plan, but in this case, it is necessary to move from the working plane to the real space, or vice versa, passage that we will present in this study. In the basic plan module already presented in other geometric and cinematic works, we want to highlight some dynamic features such as static balancing, total balancing and determination of the strength of the module after balancing. The forces that appear in the unbalanced base module were also presented in other papers, so we want to fill in only the aspects of the already balanced module forces in this study. The mechanism in Fig. 1 (planar cinematic chain) must be balanced to have a normal operation. Through a total static balancing, balancing the gravitational forces and moments generated by the forces of gravity is achieved, balancing the forces of inertia and the moments (couples) generated by the presence of inertial forces (not to be confused with the inertial moments of the mechanism, which appear separately from the other forces, being part of the inertial torsion of a mechanism and depending on both the inertial masses of the mechanism and its angular accelerations. Balancing the mechanism can be done through various methods. Partial balancing is achieved almost in all cases where the actuators (electric drive motors) are fitted with a mechanical reduction, a mechanical transmission, a sprocket, spiral gear, spool screw type. Such a reducer called the unisens (the movement allowed by it is a two-way rotation, but the transmission of the force and the motor moment can only be done in one direction, from the spindle to the worm gear, vice versa from the worm gear to the screw the force cannot be transmitted and the movement is not possible by blocking the mechanism, which makes it apt to transmit the movement from the wheel of a vehicle to its wheels in the steering mechanism, not allowing the wheel forces due to the unevenness of the ground, to be transmitted to the steering wheel and implicitly to the driver, or this mechanism is suitable for mechanical meters so that they do not twist and vice versa etc.) can balance the transmission by letting the forces and motor moments unfold, but not allowing the kinematic elements to influence the movement through their forces of weight and inertia. This results in a "forced" drive balancing from the transmission, which makes the operation of the assembly to be correct but rigid and with mechanical shocks. Such balancing is not possible when the actuators directly actuate the elements of the kinematic chain without using mechanical reducers.
\end{abstract}

Keywords: Anthropomorphic Mechatronic Systems, Robots, Total Static Balancing, Kinetostatics 


\section{Introduction}

Anthropomorphic mechatronic systems are the most widely used robotics systems worldwide today in industry and in all automated environments. These systems are best suited to the modern automation and mechatronisation needs of the modern world, being mobile, dynamic, light, robust, complex, technologically simple, easy to design and manufactured, implemented, maintained and used in almost any industrial site, both in machine building and in special environments, such as chemical, toxic, dyeing, underwater, nuclear, in space.... Anthropomorphic robots are flexible, dynamic, stable, lightweight, fast, fast, inexpensive, easy-to-install, mechanical, mechanical, mechanical and mechanical systems with a pleasant appearance, modern industrial design and easy to design and implement in any workplace, imposed. The anthropomorphic robots are part of the classical series of mechatronic systems, being in the form of arms and having at least three space rotation, to which other components may eventually be added, thus lengthening the entire kinematic chain. You can also add all the planetary or spatial rotating arms or others that are translating. At the end we always have the end effector element that can be a manipulator, that is, a hand to grasp the objects, in which case one can speak of a prehensive device, that is a gripping device that today imitates very well a human hand even if it is one mechanical, may also be a painting, cutting or welding device, or one for machining. The base support and schematics of all anthropomorphic robots remain the $3 \mathrm{R}$ space system. It has been presented in other works and studied matrix spatially, or more simply in a plan, but in this case, it is necessary to move from the working plane to the real space, or vice versa. In the basic plan module already presented in other geometric and cinematic works, we want to highlight some dynamic features such as static balancing, total balancing and determination of the strength of the module after balancing. The forces that appear in the unbalanced base module were also presented in other papers, so we want to fill in only the aspects of the already balanced module forces in this study (Antonescu and Petrescu, 1985; 1989; Antonescu et al., 1985a; 1985b; 1986; 1987; 1988; 1994; 1997; 2000a; 2000b; 2001; Aversa et al., 2017a; 2017b; 2017c; 2017d; 2017e; 2016a; 2016b; 2016c; 2016d; 2016e; 2016f; 2016g; 2016h; 2016i; 2016j; 2016k; 2016l; 2016m; 2016n; 2016o; Berto et al., 2016a; 2016b; 2016c; 2016d; Cao et al., 2013; Dong et al., 2013; Comanescu, 2010; Franklin, 1930; He et al., 2013; Lee, 2013; Lin et al., 2013; Liu et al., 2013; Mirsayar et al., 2017; Padula and Perdereau, 2013; Perumaal and Jawahar, 2013; Petrescu, 2011; 2015a; 2015b; Petrescu and Petrescu, 1995a; 1995b; 1997a; 1997b; 1997c; 2000a; 2000b; 2002a; 2002b; 2003; 2005a; 2005b; 2005c; 2005d; 2005e; 2011; 2012a; 2012b; 2013a; 2013b; 2016a; 2016; 2016c; Petrescu et al., 2009; 2016; 2017a; 2017b; 2017c; 2017d; 2017e; 2017f; 2017g; 2017h; 2017i; 2017j; 2017k; 2017l; 2017m; 2017n; 2017o; 2017p; 2017q; 2017r; 2017s; 2017t; 2017u; 2017v; 2017w; 2017x; 2017y; 2017z; 2017aa; 2017ab; 2017ac; 2017ad; 2017ae).

\section{Materials and Methods (Total Static Balancing of the Planar Kinematic Chain by the Classical Method (with Counterweight))}

Figure 1 shows the kinematic diagram of the planar chain and Fig. 2 shows the kinematic scheme of the space chain.

The mechanism in Fig. 1 (planar cinematic chain) must be balanced to have a normal operation.

Through a total static balancing, balancing the gravitational forces and moments generated by the forces of gravity is achieved, balancing the forces of inertia and the moments (couples) generated by the presence of inertial forces (not to be confused with the inertial moments of the mechanism, which appear separately from the other forces, being part of the inertial torsion of a mechanism and depending on both the inertial masses of the mechanism and its angular accelerations.

Balancing the mechanism can be done through various methods.

Partial balancing is achieved almost in all cases where the actuators (electric drive motors) are fitted with a mechanical reduction, a mechanical transmission, a sprocket, spiral gear, spool screw type.

Such a reducer called the unisons (the movement allowed by it is a two-way rotation, but the transmission of the force and the motor moment can only be done in one direction, from the spindle to the worm gear, vice versa from the worm gear to the screw the force can not be transmitted and the movement is not possible by blocking the mechanism, which makes it apt to transmit the movement from the wheel of a vehicle to its wheels in the steering mechanism, not allowing the wheel forces due to the unevenness of the ground, to be transmitted to the steering wheel and implicitly to the driver, or this mechanism is suitable for mechanical meters so that they do not twist and vice versa etc.) can balance the transmission by letting the forces and motor moments unfold, but not allowing the kinematic elements to influence the movement through their forces of weight and inertia.

This results in a "forced" drive balancing from the transmission, which makes the operation of the assembly to be correct but rigid and with mechanical shocks.

Such balancing is not possible when the actuators directly actuate the elements of the kinematic chain without using mechanical reducers. It is necessary in this situation for a real, permanent balancing. 


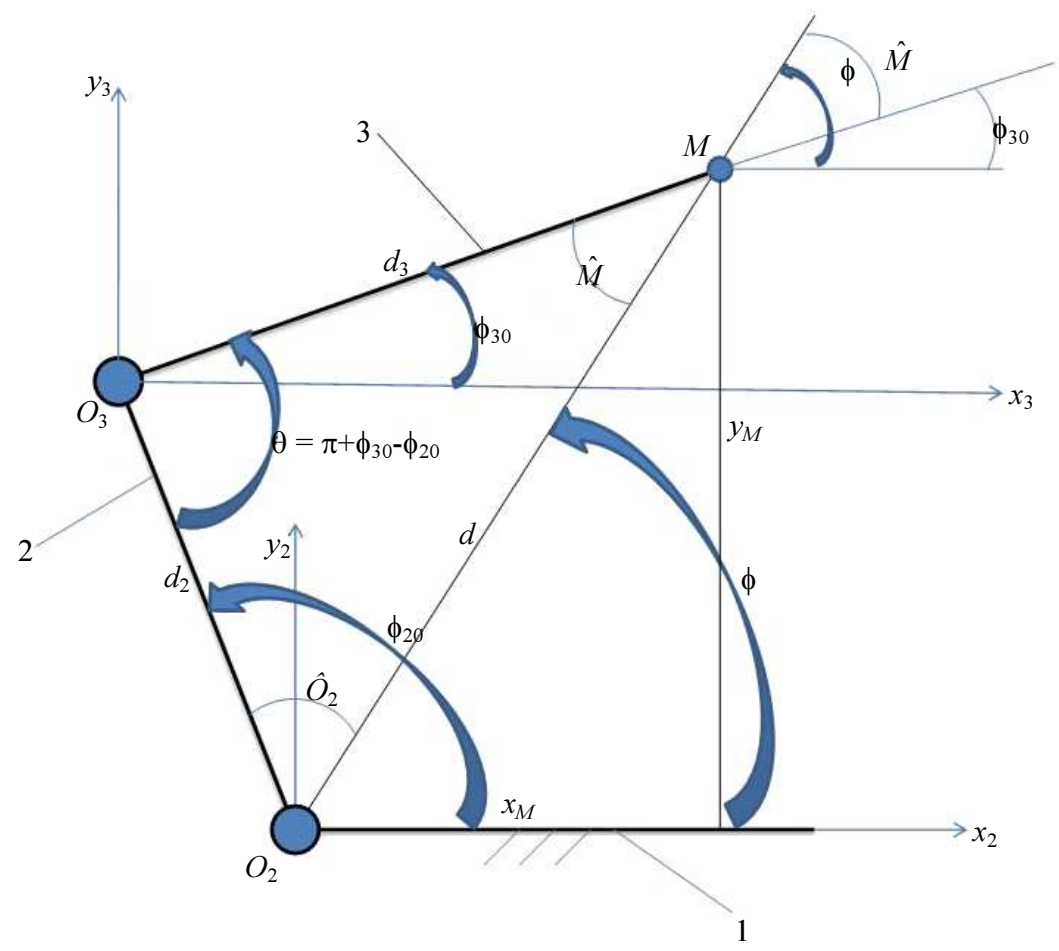

Fig. 1: The kinematic scheme of the plan chain

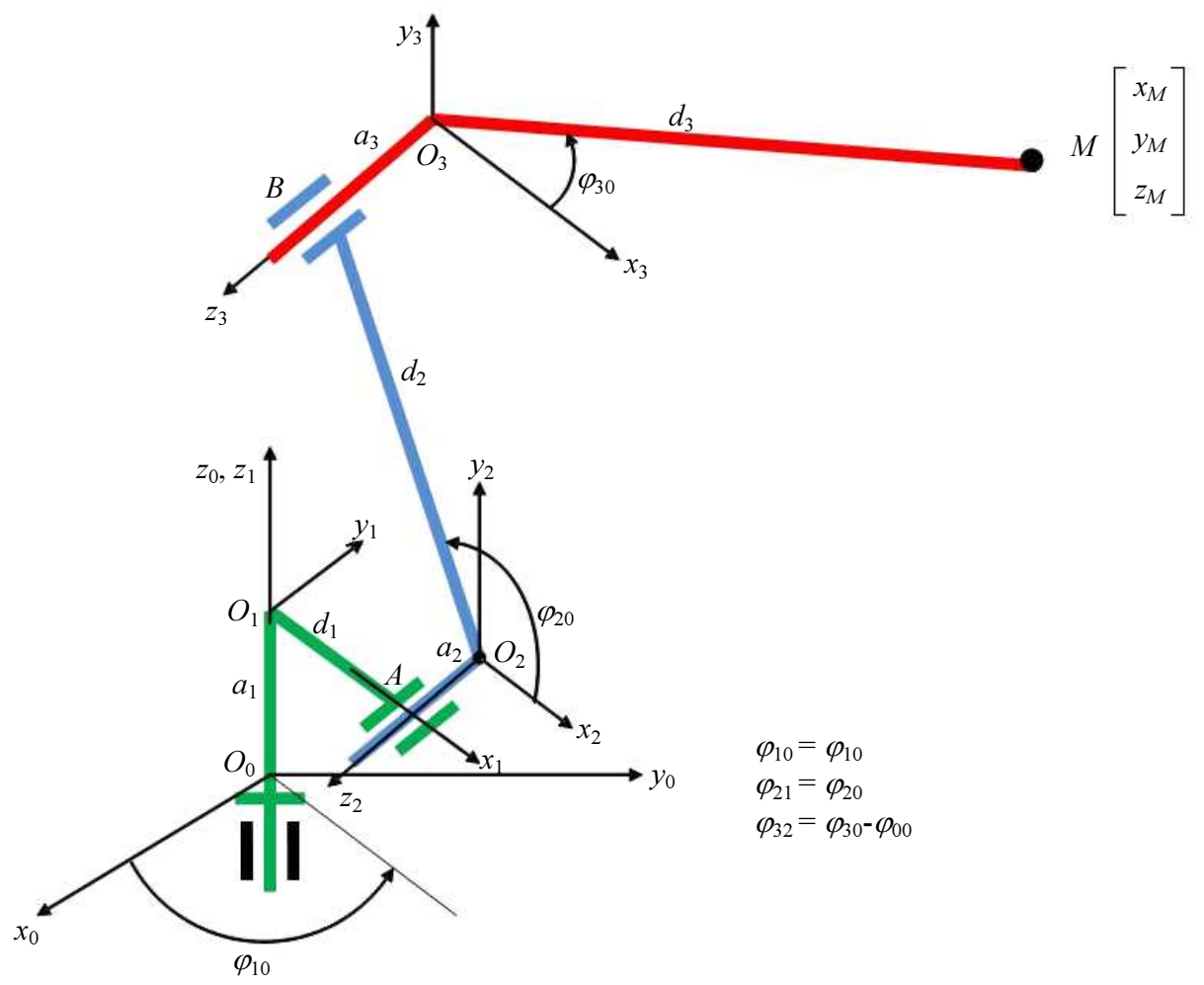

Fig. 2: The kinematic scheme of the spatial chain 
In addition, in situations where hypoid reducers are used, it is also good to have a permanent, permanent static balancing that achieves a normal, quiet operation of the mechanism and the whole assembly.

As has already been shown, by balancing the static totality of a mobile cinematic chain, it is possible to balance the weight forces and couples produced by them, as well as balancing the inertial forces and the couples produced by them, but not balancing the moment of inertia.

Arcing balancing methods generally did not work very well, the springs having to be very well calibrated, so that the elastic forces realized (stored) by them are neither too small (insufficient balancing) nor too large (because prematurely kinematic elements and couplers and also greatly forces actuators).

The most used method is the classic one, with additional counterweight masses, similar to traditional folk fountains.

Total balancing of the open robotic kinematic chain is shown in Fig. 3.

Write the sum of the moments of the weight forces on element 3 relative to point $O_{3}$ (relation 1):

$$
\sum M_{O_{3}}^{(3)}=0 \Rightarrow m_{s} \cdot d_{3}+m_{3} \cdot s_{3}=m_{I I I} \cdot \rho_{3}
$$

Thus, the weight of the endefector load (with the mass carried by it) at the distance $d_{3}$ to $O_{3}$, plus the mass of the bulkhead 3 centered in the center or weight $s_{3}$ at the distance $s_{3}$ from the $O_{3}$ point, are balanced by the weight of the supplementary mass $m_{I I I}$ is mounted at a distance $\rho_{3}$ from the $O_{3}$ joint on the other side (i.e., on the extension of element 3 ). The balancing is like a scraper, or a lever of degree 1.

In general, the $m_{I I I}$ balancing mass is chosen and the mounting distance $\rho_{3}$ (relationship 2) is calculated by computing:

$$
\rho_{3}=\frac{m_{s} \cdot d_{3}+m_{3} \cdot s_{3}}{m_{I I I}}
$$

After balancing, the mass of the element 3 concentrated in the $\mathrm{O}_{3}$ joint acquires the value of $m_{3}$ 'given by the relationship (3):

$$
m_{3^{\prime}}=m_{3}+m_{s}+m_{I I I}
$$

The sum of the moments of the weight forces on elements 2 and 3 (considered as a common platform) with respect to $\mathrm{O}_{2}$ (relationship 4) is written. The mass of element 3 is the final one obtained after balancing, $m_{3}$ 'and positioned (concentrated) at point $O_{3}$ :

$$
\sum M_{O_{2}}^{(2+3)}=0 \Rightarrow m_{3^{\prime}} \cdot d_{2}+m_{2} \cdot s_{2}=m_{I I} \cdot \rho_{2}
$$

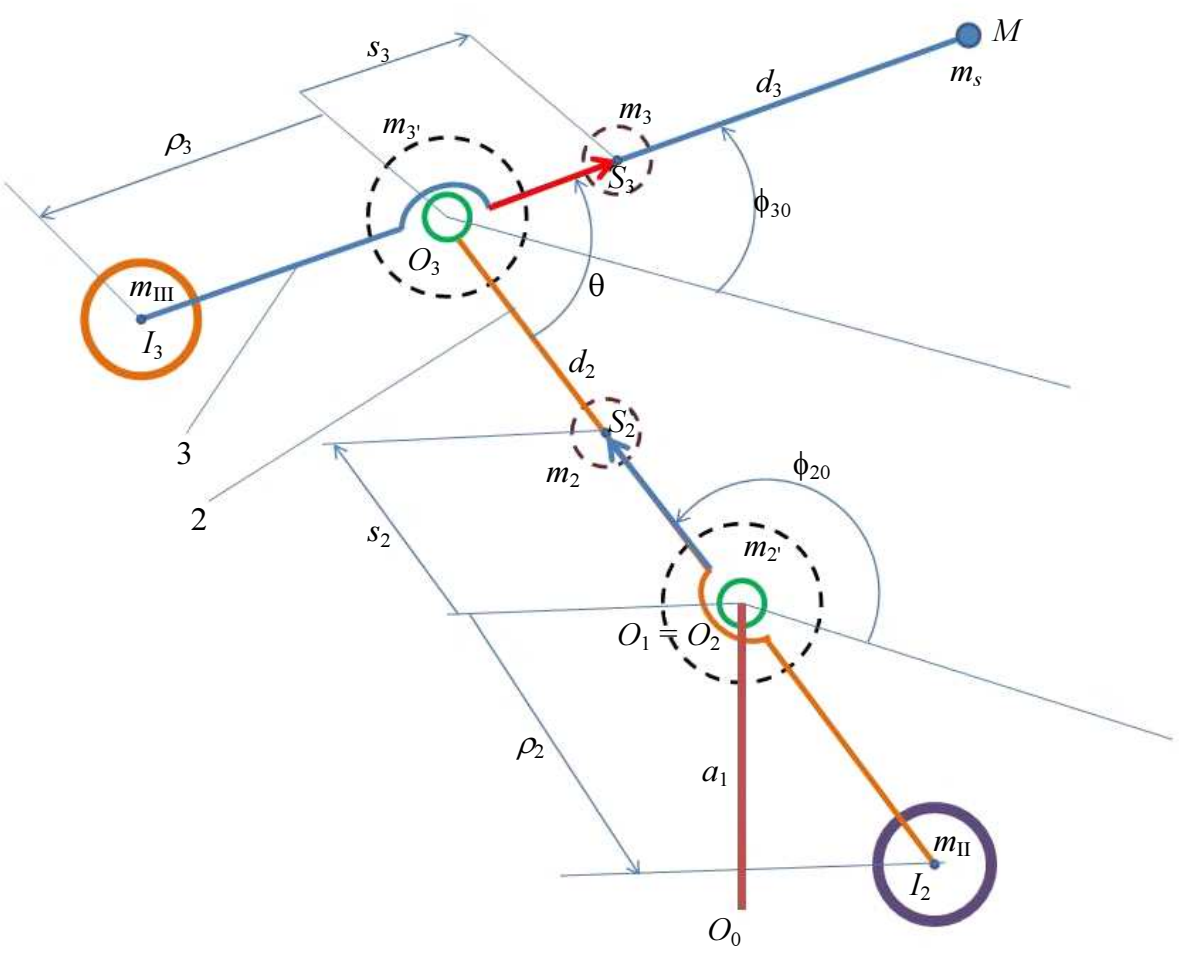

Fig. 3: Balancing the plan cinematic chain 
Generally choose the $m_{I I}$ balancing mass and calculate the mounting distance, $\rho_{2}$ (relationship 5):

$\rho_{2}=\frac{m_{3^{\prime}} \cdot d_{2}+m_{2} \cdot s_{2}}{m_{I I}}$

After balancing the mass of the entire planar kinematic chain (consisting of elements 2+3) is concentrated in the $\mathrm{O}_{2}$ joint and gets the value $m_{2}$ 'given by the relationship (6):

$m_{2^{\prime}}=m_{3^{\prime}}+m_{2}+m_{I I}$

Theoretical justification of the method used:

The forces whose moments must be written against a joint (fixed or mobile) are all parallel to each other, oriented vertically downwards (or upwardly with negative values) and have the value (module) given by the product between that mass and the gravitational acceleration.

If in moments relation we simplify everywhere with $g$, then this sum of moments appears as a sum of masses amplified each with the arm of that force.

But also the arms of the forces are similar to the distances from the point where the mass is concentrated to the articulation against which the moments of the weight forces are written, so that all arms of the weight forces can be replaced with the respective distances.
Finally, the relation of the moments of the weight forces to the joint will be the sum of the mass products away. This is more convenient, but it can only be used after appropriate theoretical justification.

\section{Results (Kinetostatic of Balanced Plan Cinematic Chain)}

The kinetostatic of the balanced plan cinematic chain means the determining of forces from this chain.

Cinetostatic means the study of the distribution of the forces of a kinematic chain by analyzing them on the whole kinematic chain, or on modules (element or several elements interconnected) considered each separately.

The study of all the forces acting within the kinematic chain is instantly made in the form of a picture of the cinematic chain in a certain position (similar to the kinematic study, which deals only with the study of the positions, velocities and accelerations of the cinematic chain instantly photographed in a certain position considered).

The forces and moments that occur in the unbalanced mechanism are more and more dispersed, but in general the mechanisms used in practice are already balanced for the sake of good functioning, so that the cinematic study of a fully balanced cinematic chain is more justified.

Starting from the well-balanced kinematic chain shown in Fig. 3, the torsion of the forces existing on this cinematic chain is instantly photographed at any position, as shown in Fig. 4.

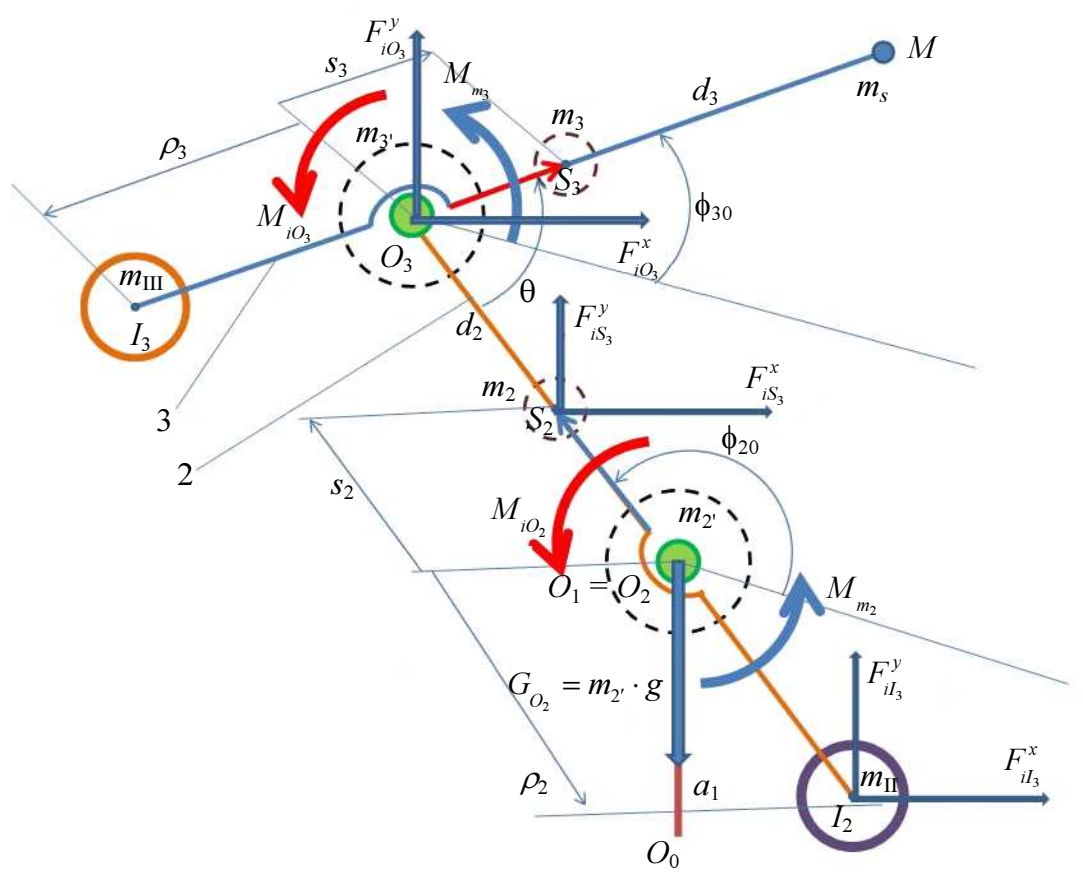

Fig. 4: The kinetostatic of the balanced plan cinematic chain 
For the beginning, the cinetostatic element of the second element, which also carries the mass $m_{3}$ 'of the element 3, so that the element 2 supports the effect of the whole balanced kinematic chain, considered welded (similar to a platform), the element 3 being replaced by the mass $m_{3^{\prime}}$, inertia and weight forces of the mass $m_{3^{\prime}}$.

Since the mechanism has already been balanced, weight forces no longer produce effects and they are removed from subsequent calculations to make drawing and relationships more difficult. It is considered to be only the final result of the weight of the entire balanced kinematic chain, $G_{O 2}$, which no longer produces any moment on this point, but only generates a vertical component of the $\mathrm{O}_{2}$ coupling reaction.

Only the inertial forces will be considered in the following cinematic calculations, with the important statement that the total static balancing actually annihilates the effects of the inertial forces, so that the study aims to present these forces to their knowledge, observing (checking) towards the end of the calculations that and their effects have been canceled by the total balancing already done.

We recall, from the kinematic study, the accelerations of the $\mathrm{O}_{3}$ point (the last two system relationships 7 positions, speeds and accelerations):

$\left\{\begin{array}{l}x_{O_{3}}=d_{2} \cdot \cos \varphi_{20} ; \quad y_{O_{3}}=d_{2} \cdot \sin \varphi_{20} ; \\ \dot{x}_{O_{3}}=-d_{2} \cdot \sin \varphi_{20} \cdot \omega_{20} ; \quad \dot{y}_{O_{3}}=d_{2} \cdot \cos \varphi_{20} \cdot \omega_{20} ; \\ \ddot{x}_{O_{3}}=-d_{2} \cdot \cos \varphi_{20} \cdot \omega_{20}^{2} ; \quad \ddot{y}_{O_{3}}=-d_{2} \cdot \sin \varphi_{20} \cdot \omega_{20}^{2}\end{array}\right.$

With the help of the relations (7) the inertia forces from the inertia torch (8) of point $O_{3}$ are written:

$$
\left\{\begin{array}{l}
F_{i O_{3}}^{x}=-m_{3^{\prime}} \cdot \ddot{x}_{O_{3}}=-m_{3^{\prime}} \cdot(-) d_{2} \cdot \cos \varphi_{20} \cdot \omega_{20}^{2} \\
=m_{3^{\prime}} \cdot d_{2} \cdot \cos \varphi_{20} \cdot \omega_{20}^{2} \\
F_{i O_{3}}^{y}=-m_{3^{\prime}} \cdot \ddot{y}_{O_{3}}=-m_{3^{\prime}} \cdot(-) d_{2} \cdot \sin \varphi_{20} \cdot \omega_{20}^{2} \\
=m_{3^{\prime}} \cdot d_{2} \cdot \sin \varphi_{20} \cdot \omega_{20}^{2} \\
M_{i O_{3}}=-J_{O_{3}} \cdot \varepsilon_{3}
\end{array}\right.
$$

From the inertia torque of the point $O_{3}$ given by the system relations (8), we are currently interested only in inertial forces at the point $O_{3}$ oriented on the axes $x$ and $y$ (basically the scalar components of the inertial force given by mass $m_{3}{ }^{\prime}$ ), they producing the effect on element 2 . We intend to write the sum of the forces acting on the 2-3 kinematic chain separated on the $x$ and $y$-axes as well as the sum of the moments of the torques produced by the inertial forces on the chain from the $\mathrm{O}_{2}$ point. In addition to $\mathrm{O}_{3}$, we also have the inertial forces given by mass $m_{2}$ from point $s_{2}$ (system relations 9) and the inertia forces given by the equilibrium mass $m_{I I}$ in point $I_{2}$ (system relations 10):

$$
\begin{gathered}
\left\{\begin{array}{l}
F_{i S_{2}}^{x}=-m_{2} \cdot \ddot{x}_{S_{2}}=m_{2} \cdot s_{2} \cdot \cos \varphi_{20} \cdot \omega_{20}^{2} \\
F_{i S_{2}}^{y}=-m_{2} \cdot \ddot{y}_{S_{2}}=m_{2} \cdot s_{2} \cdot \sin \varphi_{20} \cdot \omega_{20}^{2}
\end{array}\right. \\
\left\{\begin{array}{l}
F_{i I_{2}}^{x}=-m_{I I} \cdot \ddot{x}_{I_{2}}=-m_{I I} \cdot \rho_{2} \cdot \cos \varphi_{20} \cdot \omega_{20}^{2} \\
F_{i I_{2}}^{y}=-m_{I I} \cdot \ddot{y}_{I_{2}}=-m_{I I} \cdot \rho_{2} \cdot \sin \varphi_{20} \cdot \omega_{20}^{2}
\end{array}\right.
\end{gathered}
$$

We have prepared the inertial forces acting on element 2 and we can begin to study the equilibrium forces equations for element 2 (but also taking into account the effects of element 3 ). First we write the equilibrium of the forces on the horizontal axis, $x$ (relations 11), from which the horizontal component of the $\mathrm{O}_{2}$ coupling reaction will finally be determined:

$$
\left\{\begin{array}{l}
\sum F_{(2)}^{x}=0 \Rightarrow m_{3^{\prime}} \cdot d_{2} \cdot \cos \varphi_{20} \cdot \omega_{20}^{2}+m_{2} \cdot s_{2} \cdot \cos \varphi_{20} \cdot \omega_{20}^{2} \\
-m_{I I} \cdot \rho_{2} \cdot \cos \varphi_{20} \cdot \omega_{20}^{2}+R_{O_{2}}^{x}=0 \\
\Rightarrow\left(m_{3^{\prime}} \cdot d_{2}+m_{2} \cdot s_{2}-m_{I I} \cdot \rho_{I I}\right) \cdot \cos \varphi_{20} \cdot \omega_{20}^{2}+R_{12}^{x}=0 \\
\text { but } m_{3^{\prime}} \cdot d_{2}+m_{2} \cdot s_{2}-m_{I I} \cdot \rho_{I I}=0 \text { dueto balanced } \\
\Rightarrow R_{O_{2}}^{x} \equiv R_{12}^{x}=0
\end{array}\right.
$$

Next, a force (equilibrium of forces) projected on the vertical axis, $y$, on element 2 (but also with respect to the loads on element 3 ) is made and determine the vertical component of the fixed coupling reaction (considered fixed) $\mathrm{O}_{2}$ (relationships 12):

$$
\left\{\begin{array}{l}
\sum F_{(2)}^{y}=0 \Rightarrow m_{3^{\prime}} \cdot d_{2} \cdot \sin \varphi_{20} \cdot \omega_{20}^{2}+m_{2} \cdot s_{2} \cdot \sin \varphi_{20} \cdot \omega_{20}^{2} \\
-m_{I I} \cdot \rho_{2} \cdot \sin \varphi_{20} \cdot \omega_{20}^{2}-m_{2} \cdot g+R_{12}^{y}=0 \\
\Rightarrow\left(m_{3^{\prime}} \cdot d_{2}+m_{2} \cdot s_{2}-m_{I I} \cdot \rho_{I I}\right) \cdot \sin \varphi_{20} \cdot \omega_{20}^{2}-m_{2^{\prime}} \cdot g+R_{12}^{y}=0 \\
\text { but } m_{3^{\prime}} \cdot d_{2}+m_{2} \cdot s_{2}-m_{I I} \cdot \rho_{I I}=0 \text { dueto balanced } \\
\Rightarrow R_{O_{2}}^{y} \equiv R_{12}^{y}=m_{2^{\prime}} \cdot g=G_{O_{2}}
\end{array}\right.
$$

It can be seen that the loads in the couplings are minimal precisely due to balancing.

The effect of inertial forces (couples produced by these forces) is canceled (due to balancing). Couples by weight are also canceled due to balancing.

Balanced final weight also produces only one effect on the kinematic chain, a vertical load (causes a vertical reaction) in the fixed coupler.

At full balancing, even horizontal load from the fixed coupler disappears.

The only remaining load is constant and therefore it does not pose a high risk of wear, it does not create dynamic shocks, the mechanism has a normal (quiet) running behavior. 
It will also write a sum of moments relative to the fixed joint on element 2 (but also considering the effects on element 3), (relations 13):

$$
\left\{\begin{array}{l}
\sum M_{O_{2}}^{(2)}=0 \Rightarrow M_{m_{2}}-F_{i O_{3}}^{x} \cdot d_{2} \cdot \cos \left(\varphi_{20}-\frac{\pi}{2}\right) \\
-F_{i O_{3}}^{y} \cdot d_{2} \cdot \sin \left(\varphi_{20}-\frac{\pi}{2}\right)-F_{i S_{2}}^{x} \cdot s_{2} \cdot \sin \varphi_{20}-F_{i S_{2}}^{y} \cdot s_{2} \cdot-\cos \varphi_{20} \\
+F_{i I_{2}}^{x} \cdot \rho_{2} \cdot \cos \left(\varphi_{20}-\frac{\pi}{2}\right)+F_{i I_{2}}^{y} \cdot \rho_{2} \cdot \sin \left(\varphi_{20}-\frac{\pi}{2}\right)+M_{i O_{2}}=0 \\
\Rightarrow M_{m_{2}}-m_{3} \cdot d_{2}^{2} \omega_{20}^{2} \cos \varphi_{20} \sin \varphi_{20}+m_{3^{\prime}} \cdot d_{2}^{2} \omega_{20}^{2} \sin \varphi_{20} \cos \varphi_{20} \\
-m_{2} \cdot s_{2}^{2} \cdot \omega_{20}^{2} \cdot \cos \varphi_{20} \cdot \sin \varphi_{20}+m_{2} \cdot s_{2}^{2} \cdot \omega_{20}^{2} \cdot \sin \varphi_{20} \cdot \cos \varphi_{20} \\
-m_{I I} \cdot \rho_{2}^{2} \cdot \omega_{20}^{2} \cos \varphi_{20} \cdot \sin \varphi_{20}+m_{I I} \cdot \rho_{2}^{2} \cdot \omega_{20}^{2} \cdot \sin \varphi_{20} \cdot \cos \varphi_{20} \\
-J_{O_{2}}^{*} \cdot \varepsilon_{2}=0 \Rightarrow M_{m_{2}}-J_{O_{2}}^{*} \cdot \varepsilon_{2}=0 \Rightarrow M_{m_{2}}=J_{O_{2}}^{*} \cdot \varepsilon_{2}
\end{array}\right.
$$

$J_{O_{2}}^{*}$ (the momentum of mass or mechanical inertia of element 2, plus the influence of the mass of element 3 ), is calculated by the relation (14):

$$
J_{O_{2}}^{*}=J_{O_{2}}+m_{3^{\prime}} \cdot d_{2}^{2}=m_{2} \cdot s_{2}^{2}+m_{I I} \cdot \rho_{2}^{2}+m_{3^{\prime}} \cdot d_{2}^{2}
$$

It follows that from the momentary equilibrium to the fixed coupler on the element 2 and considering the influence of the element 3 , it is possible to determine the necessary motor moment, which must be generated by the actuator 2, mounted in the coupling $O_{2}$ (relation 15).

$$
M_{m_{2}}=J_{O_{2}}^{*} \cdot \varepsilon_{2}=\left(m_{2} \cdot s_{2}^{2}+m_{I I} \cdot \rho_{2}^{2}+m_{3} \cdot d_{2}^{2}\right) \cdot \ddot{\varphi}_{20}
$$

Observation. The motor torque 3 only acts on the element 3 broken by the element 2 (i.e., it is an action of 3 relative to 2 , or more precisely the element 3 is actuated by the element 2 by this motor moment 2 ). Nor was the moment of inertia considered for the same reasons. It acts only on element 3 considered separately (broken by 2 ). The influence of the mass $m_{3}$ 'on element 2 is shown by the final mass $m_{2}$ which also contains the mass $m_{3}$ '.

This is followed by the separate cinetostatic study of element 3 broken by element 2 . To make this study much easier, the following considerations will be taken into consideration: All the forces of weight and inertia acting on element 3 are already balanced so that they no longer influence the dynamics element. Neither the gravitational forces nor the inertial forces no longer couples at the $O_{3}$ reduction point, as these couples are all canceled due to element balancing. Making the sum of the moments of all forces on the element 3 relative to the mobile $O_{3}$, (relation 16) we will observe that the motor moment $M_{m_{3}}$ of the actuator 3 is only balanced with the $M_{O_{3}}$ moment of inertia:

$$
\begin{aligned}
& \sum M_{O_{3}}^{(3)}=0 \Rightarrow \\
& M_{m_{3}}+M_{i O_{3}}=0 \Rightarrow M_{m_{3}}-J_{O_{3}} \cdot \varepsilon_{3}=0 \Rightarrow M_{m_{3}}=J_{O_{3}} \cdot \varepsilon_{3} \\
& \Rightarrow M_{m_{3}}=\left(m_{s} \cdot d_{3}^{2}+m_{3} \cdot s_{3}^{2}+m_{I I} \cdot \rho_{3}^{2}\right) \cdot \ddot{\varphi}_{30}
\end{aligned}
$$

The vertical component of the inner cup $\mathrm{O}_{3}$ reaction is determined by realizing the equilibrium projections on the $y$-axis of all the forces acting on the element 3 (relation 17):

$$
\left\{\begin{array}{l}
\sum F_{(3)}^{y}=0 \Rightarrow-m_{3^{\prime}} \cdot g+R_{23}^{y}=0 \\
\Rightarrow R_{23}^{y}=m_{3^{\prime}} \cdot g \\
\Rightarrow R_{32}^{y}=-R_{23}^{y}=-m_{3^{\prime}} \cdot g
\end{array}\right.
$$

The horizontal component of the reaction from the mobile kinematic couple $O_{3}$ is null $\left(R_{23}^{x}=-R_{32}^{y}=0\right)$.

\section{Discussion}

The mechanism in Fig. 1 (planar cinematic chain) must be balanced to have a normal operation.

Through a total static balancing, balancing the gravitational forces and moments generated by the forces of gravity is achieved, balancing the forces of inertia and the moments (couples) generated by the presence of inertial forces (not to be confused with the inertial moments of the mechanism, which appear separately from the other forces, being part of the inertial torsion of a mechanism and depending on both the inertial masses of the mechanism and its angular accelerations.

Balancing the mechanism can be done through various methods.

Partial balancing is achieved almost in all cases where the actuators (electric drive motors) are fitted with a mechanical reduction, a mechanical transmission, a sprocket, spiral gear, spool screw type.

Such a reducer called the unisens (the movement allowed by it is a two-way rotation, but the transmission of the force and the motor moment can only be done in one direction, from the spindle to the worm gear, vice versa from the worm gear to the screw screw the force cannot be transmitted and the movement is not possible by blocking the mechanism, which makes it apt to transmit the movement from the wheel of a vehicle to its wheels in the steering mechanism, not allowing the wheel forces due to the unevenness of the ground, to be transmitted to the steering wheel and implicitly to the driver, or this mechanism is suitable for mechanical meters so that they do not twist and vice versa etc.) can balance the transmission by letting the forces and motor moments unfold, but not allowing the kinematic elements to influence the movement through their forces of weight and inertia. 
This results in a "forced" drive balancing from the transmission, which makes the operation of the assembly to be correct but rigid and with mechanical shocks.

Such balancing is not possible when the actuators directly actuate the elements of the kinematic chain without using mechanical reducers. It is necessary in this situation for a real, permanent balancing.

In addition, in situations where hypoid reducers are used, it is also good to have a permanent, permanent static balancing that achieves a normal, quiet operation of the mechanism and the whole assembly.

As has already been shown, by balancing the static totality of a mobile cinematic chain, it is possible to balance the weight forces and couples produced by them, as well as balancing the inertial forces and the couples produced by them, but not balancing the moment of inertia.

Arcing balancing methods generally did not work very well, the springs having to be very well calibrated, so that the elastic forces realized (stored) by them are neither too small (insufficient balancing) nor too large (because prematurely kinematic elements and couplers and also greatly forces actuators).

The most used method is the classic one, with additional counterweight masses, similar to traditional folk fountains.

Total balancing of the open robotic kinematic chain is shown in Fig. 3.

\section{Conclusion}

Through a total static balancing, balancing the gravitational forces and moments generated by the forces of gravity is achieved, balancing the forces of inertia and the moments (couples) generated by the presence of inertial forces (not to be confused with the inertial moments of the mechanism, which appear separately from the other forces, being part of the inertial torsion of a mechanism and depending on both the inertial masses of the mechanism and its angular accelerations.

Balancing the mechanism can be done through various methods. Partial balancing is achieved almost in all cases where the actuators (electric drive motors) are fitted with a mechanical reduction, a mechanical transmission, a sprocket, spiral gear, spool screw type.

Such a reducer called the unisens (the movement allowed by it is a two-way rotation, but the transmission of the force and the motor moment can only be done in one direction, from the spindle to the worm gear, vice versa from the worm gear to the screw the force cannot be transmitted and the movement is not possible by blocking the mechanism, which makes it apt to transmit the movement from the wheel of a vehicle to its wheels in the steering mechanism, not allowing the wheel forces due to the unevenness of the ground, to be transmitted to the steering wheel and implicitly to the driver, or this mechanism is suitable for mechanical meters so that they do not twist and vice versa etc.) can balance the transmission by letting the forces and motor moments unfold, but not allowing the kinematic elements to influence the movement through their forces of weight and inertia.

This results in a "forced" drive balancing from the transmission, which makes the operation of the assembly to be correct but rigid and with mechanical shocks.

Such balancing is not possible when the actuators directly actuate the elements of the kinematic chain without using mechanical reducers.

\section{Acknowledgement}

This text was acknowledged and appreciated by Dr. Veturia CHIROIU Honorific member of Technical Sciences Academy of Romania (ASTR) PhD supervisor in Mechanical Engineering.

\section{Funding Information}

Research contract: 1-Research contract: Contract number 36-5-4D/1986 from 24IV1985, beneficiary CNST RO (Romanian National Center for Science and Technology) Improving dynamic mechanisms.

2-Contract research integration. 19-91-3 from 29.03.1991; Beneficiary: MIS; TOPIC: Research on designing mechanisms with bars, cams and gears, with application in industrial robots.

3-Contract research. GR 69/10.05.2007: NURC in 2762; theme 8: Dynamic analysis of mechanisms and manipulators with bars and gears.

4-Labor contract, no. 35/22.01.2013, the UPB, "Stand for reading performance parameters of kinematics and dynamic mechanisms, using inductive and incremental encoders, to a Mitsubishi Mechatronic System" "PN-IIIN-CI-2012-1-0389".

All these matters are copyrighted! Copyrights: 394qodGnhhtej, from 17-02-2010 13:42:18; 463-vpstuCGsiy, from 20-03-2010 12:45:30; 631-sqfsgqvutm, from 2405-2010 16:15:22; 933-CrDztEfqow, from 07-01-2011 13:37:52.

\section{Author's Contributions}

This section should state the contributions made by each author in the preparation, development and publication of this manuscript.

\section{Ethics}

Authors should address any ethical issues that may arise after the publication of this manuscript. 


\section{References}

Antonescu, P. and F. Petrescu, 1985. An analytical method of synthesis of cam mechanism and flat stick. Proceedings of the 4th International Symposium on Theory and Practice of Mechanisms, (TPM' 89), Bucharest.

Antonescu, P. and F. Petrescu, 1989. Contributions to kinetoplast dynamic analysis of distribution mechanisms. Bucharest.

Antonescu, P., M. Oprean and F. Petrescu, 1985a. Contributions to the synthesis of oscillating cam mechanism and oscillating flat stick. Proceedings of the 4th International Symposium on Theory and Practice of Mechanisms, (TPM' 85), Bucharest.

Antonescu, P., M. Oprean and F. Petrescu, 1985b. At the projection of the oscillate cams, there are mechanisms and distribution variables. Proceedings of the 5th Conference of Engines, Automobiles, Tractors and Agricultural Machines, (TAM' 58), Imotors and cars, Brasov.

Antonescu, P., M. Oprean and F. Petrescu, 1986. Projection of the profile of the rotating camshaft acting on the oscillating plate with disengagement. Proceedings of the 3rd National Computer-aided Design Symposium in the field of Mechanisms and Machine Parts, (MMP' 86), Brasov.

Antonescu, P., M. Oprean and F. Petrescu, 1987. Dynamic analysis of the cam distribution mechanisms. Proceedings of the 7th National Symposium on Industrial Robots and Space Mechanisms, (RSM' 87), Bucharest.

Antonescu, P., M. Oprean and F. Petrescu, 1988. Analytical synthesis of Kurz profile, rotating the flat cam. Mach, Build. Rev.

Antonescu, P., F. Petrescu and O. Antonescu, 1994. Contributions to the synthesis of the rotating cam mechanism and the tip of the balancing tip. Brasov.

Antonescu, P., F. Petrescu and D. Antonescu, 1997. Geometrical synthesis of the rotary cam and balance tappet mechanism. Bucharest. 3: 23-23.

Antonescu, P., F. Petrescu and O. Antonescu, 2000a. Contributions to the synthesis of the rotary disc-cam profile. Proceedings of the 8th International Conference on the Theory of Machines and Mechanisms, (TMM' 00), Liberec, Czech Republic, pp: 51-56.

Antonescu, P., F. Petrescu and O. Antonescu, $2000 \mathrm{~b}$. Synthesis of the rotary cam profile with balance follower. Proceedings of the 8th Symposium on Mechanisms and Mechanical Transmissions, (MMT'00), Timişoara, pp: 39-44.

Antonescu, P., F. Petrescu and O. Antonescu, 2001. Contributions to the synthesis of mechanisms with rotary disc-cam. Proceedings of the 8th IFToMM International Symposium on Theory of Machines and Mechanisms, (TMM' 01), Bucharest, ROMANIA, pp: 31-36.
Aversa, R., F.I.T. Petrescu, R.V. Petrescu and A. Apicella, 2016a. Biomimetic FEA bone modeling for customized hybrid biological prostheses development. Am. J. Applied Sci., 13: 1060-1067. DOI: 10.3844/ajassp.2016.1060.1067

Aversa, R., D. Parcesepe, R.V. Petrescu, G. Chen and F.I.T. Petrescu et al., 2016b. Glassy amorphous metal injection molded induced morphological defects. Am. J. Applied Sci., 13: 1476-1482. DOI: 10.3844/ajassp.2016.1476.1482

Aversa, R., R.V. Petrescu, F.I.T. Petrescu and A. Apicella, 2016c. Smart-factory: Optimization and process control of composite centrifuged pipes. Am. J. Applied Sci., 13: 1330-1341. DOI: 10.3844/ajassp.2016.1330.1341

Aversa, R., F. Tamburrino, R.V. Petrescu, F.I.T. Petrescu and M. Artur et al., 2016d. Biomechanically inspired shape memory effect machines driven by muscle like acting NiTi alloys. Am. J. Applied Sci., 13: 1264-1271. DOI: 10.3844/ajassp.2016.1264.1271

Aversa, R., E.M. Buzea, R.V. Petrescu, A. Apicella and M. Neacsa et al., 2016e. Present a mechatronic system having able to determine the concentration of carotenoids. Am. J. Eng. Applied Sci., 9: 1106-1111. DOI: 10.3844/ajeassp.2016.1106.1111

Aversa, R., R.V. Petrescu, R. Sorrentino, F.I.T. Petrescu and A. Apicella, 2016f. Hybrid ceramo-polymeric nanocomposite for biomimetic scaffolds design and preparation. Am. J. Eng. Applied Sci., 9: 1096-1105. DOI: 10.3844/ajeassp.2016.1096.1105

Aversa, R., V. Perrotta, R.V. Petrescu, C. Misiano and F.I.T. Petrescu et al., 2016g. From structural colors to super-hydrophobicity and achromatic transparent protective coatings: Ion plating plasma assisted $\mathrm{TiO}_{2}$ and $\mathrm{SiO}_{2}$ Nano-film deposition. Am. J. Eng. Applied Sci., 9: 1037-1045.

DOI: 10.3844/ajeassp.2016.1037.1045

Aversa, R., R.V. Petrescu, F.I.T. Petrescu and A. Apicella, 2016h. Biomimetic and evolutionary design driven innovation in sustainable products development. Am. J. Eng. Applied Sci., 9: 1027-1036. DOI: 10.3844/ajeassp.2016.1027.1036

Aversa, R., R.V. Petrescu, A. Apicella and F.I.T. Petrescu, 2016i. Mitochondria are naturally micro robots-a review. Am. J. Eng. Applied Sci., 9: 991-1002. DOI: 10.3844/ajeassp.2016.991.1002

Aversa, R., R.V. Petrescu, A. Apicella and F.I.T. Petrescu, 2016j. We are addicted to vitamins $\mathrm{C}$ and EA review. Am. J. Eng. Applied Sci., 9: 1003-1018. DOI: 10.3844/ajeassp.2016.1003.1018

Aversa, R., R.V. Petrescu, A. Apicella and F.I.T. Petrescu, 2016k. Physiologic human fluids and swelling behavior of hydrophilic biocompatible hybrid ceramo-polymeric materials. Am. J. Eng. Applied Sci., 9: 962-972. DOI: 10.3844/ajeassp.2016.962.972 
Aversa, R., R.V. Petrescu, A. Apicella and F.I.T. Petrescu, 20161. One can slow down the aging through antioxidants. Am. J. Eng. Applied Sci., 9: 1112-1126. DOI: 10.3844/ajeassp.2016.1112.1126

Aversa, R., R.V. Petrescu, A. Apicella and F.I.T. Petrescu, 2016m. About homeopathy or «Similia similibus curentur $\gg$. Am. J. Eng. Applied Sci., 9: 1164-1172. DOI: 10.3844/ajeassp.2016.1164.1172

Aversa, R., R.V. Petrescu, A. Apicella and F.I.T. Petrescu, 2016n. The basic elements of life's. Am. J. Eng. Applied Sci., 9: 1189-1197.

DOI: 10.3844/ajeassp.2016.1189.1197

Aversa, R., F.I.T. Petrescu, R.V. Petrescu and A. Apicella, 2016o. Flexible stem trabecular prostheses. Am. J. Eng. Applied Sci., 9: 1213-1221. DOI: 10.3844/ajeassp.2016.1213.1221

Aversa, R., R.V.V. Petrescu, A. Apicella and F.I.T. Petrescu, 2017a. Nano-diamond hybrid materials for structural biomedical application. Am. J. Biochem. Biotechnol., 13: 34-41. DOI: 10.3844/ajbbsp.2017.34.41

Aversa, R., R.V. Petrescu, B. Akash, R.B. Bucinell and J.M. Corchado et al., 2017b. Kinematics and forces to a new model forging manipulator. Am. J. Applied Sci., 14: 60-80. DOI: 10.3844/ajassp.2017.60.80

Aversa, R., R.V. Petrescu, A. Apicella, I.T.F. Petrescu and J.K. Calautit et al., 2017c. Something about the $\mathrm{V}$ engines design. Am. J. Applied Sci., 14: 34-52. DOI: 10.3844/ajassp.2017.34.52

Aversa, R., D. Parcesepe, R.V.V. Petrescu, F. Berto and G. Chen et al., 2017d. Process ability of bulk metallic glasses. Am. J. Applied Sci., 14: 294-301. DOI: 10.3844/ajassp.2017.294.301

Aversa, R., R.V.V. Petrescu, B. Akash, R.B. Bucinell and J.M. Corchado et al., 2017e. Something about the balancing of thermal motors. Am. J. Eng. Applied Sci., 10: 200.217.

DOI: 10.3844/ajeassp.2017.200.217

Berto, F., R.V.V. Petrescu and F.I.T. Petrescu, 2016a. A review of recent results on $3 \mathrm{D}$ effects. Am. J. Eng. Applied Sci., 9: 1247-1260. DOI: 10.3844/ajeassp.2016.1247.1260

Berto, F., R.V.V. Petrescu and F.I.T. Petrescu, $2016 \mathrm{~b}$. Three-dimensional in bonded joints: A short review. Am. J. Eng. Applied Sci., 9: 1261-1268. DOI: 10.3844/ajeassp.2016.1261.1268

Berto, F., A. Gagani, R.V.V. Petrescu and F.I.T. Petrescu, 2016c. Key-hole notches in isostatic graphite: A review of some recent data. Am. J. Eng. Applied Sci., 9: 1292-1300. DOI: 10.3844/ajeassp.2016.1292.1300

Berto, F., A. Gagani, R. Aversa, R.V.V. Petrescu and A. Apicella et al., 2016d. Multiaxial fatigue strength to notched specimens made of 40CrMoV13.9. Am. J. Eng. Applied Sci., 9: 1269-1291.

DOI: 10.3844/ajeassp.2016.1269.1291
Cao, W., H. Ding, Z. Bin and C. Ziming, 2013. New structural representation and digital-analysis platform for symmetrical parallel mechanisms. Int. J. Adv. Robotic Sys. DOI: 10.5772/56380

Comanescu, A., 2010. Bazele Modelarii Mecanismelor. 1st Edn., E. Politeh. Press, Bucureşti, pp: 274.

Dong, H., N. Giakoumidis, N. Figueroa and N. Mavridis, 2013. Approaching behaviour monitor and vibration indication in developing a General Moving Object Alarm System (GMOAS). Int. J. Adv. Robotic Sys. DOI: $10.5772 / 56586$

Franklin, D.J., 1930. Ingenious Mechanisms for Designers and Inventors. 1st Edn., Industrial Press Publisher.

He, B., Z. Wang, Q. Li, H. Xie and R. Shen, 2013. An analytic method for the kinematics and dynamics of a multiple-backbone continuum robot. IJARS. DOI: $10.5772 / 54051$

Lee, B.J., 2013. Geometrical derivation of differential kinematics to calibrate model parameters of flexible manipulator. Int. J. Adv. Robotic Sys. DOI: $10.5772 / 55592$

Lin, W., B. Li, X. Yang and D. Zhang, 2013. Modelling and control of inverse dynamics for a 5-DOF parallel kinematic polishing machine. Int. J. Adv. Robotic Sys. DOI: 10.5772/54966

Liu, H., W. Zhou, X. Lai and S. Zhu, 2013. An efficient inverse kinematic algorithm for a PUMA560structured robot manipulator. IJARS. DOI: $10.5772 / 56403$

Mirsayar, M.M., V.A. Joneidi, R.V.V. Petrescu, F.I.T. Petrescu and F. Berto, 2017. Extended MTSN criterion for fracture analysis of soda lime glass. Eng. Fracture Mechan., 178: 50-59. DOI: 10.1016/j.engfracmech.2017.04.018

Padula, F. and V. Perdereau, 2013. An on-line path planner for industrial manipulators. Int. J. Adv. Robotic Sys. DOI: 10.5772/55063

Perumaal, S. and N. Jawahar, 2013. Automated trajectory planner of industrial robot for pick-andplace task. IJARS. DOI: 10.5772/53940

Petrescu, F. and R. Petrescu, 1995a. Contributions to optimization of the polynomial motion laws of the stick from the internal combustion engine distribution mechanism. Bucharest, 1: 249-256.

Petrescu, F. and R. Petrescu, 1995b. Contributions to the synthesis of internal combustion engine distribution mechanisms. Bucharest, 1: 257-264.

Petrescu, F. and R. Petrescu, 1997a. Dynamics of cam mechanisms (exemplified on the classic distribution mechanism). Bucharest, 3: 353-358.

Petrescu, F. and R. Petrescu, 1997b. Contributions to the synthesis of the distribution mechanisms of internal combustion engines with a Cartesian coordinate method. Bucharest, 3: 359-364. 
Petrescu, F. and R. Petrescu, 1997c. Contributions to maximizing polynomial laws for the active stroke of the distribution mechanism from internal combustion engines. Bucharest, 3: 365-370.

Petrescu, F. and R. Petrescu, 2000a. Synthesis of distribution mechanisms by the rectangular (Cartesian) coordinate method. Proceedings of the 8th National Conference on International Participation, (CIP' 00), Craiova, Romania, pp: 297-302.

Petrescu, F. and R. Petrescu, 2000b. The design (synthesis) of cams using the polar coordinate method (triangle method). Proceedings of the 8th National Conference on International Participation, (CIP' 00), Craiova, Romania, pp: 291-296.

Petrescu, F. and R. Petrescu, 2002a. Motion laws for cams. Proceedings of the International Computer Assisted Design, National Symposium with Participation, (SNP' 02), Braşov, pp: 321-326.

Petrescu, F. and R. Petrescu, 2002b. Camshaft dynamics elements. Proceedings of the International Computer Assisted Design, National Participation Symposium, (SNP' 02), Braşov, pp: 327-332.

Petrescu, F. and R. Petrescu, 2003. Some elements regarding the improvement of the engine design. Proceedings of the National Symposium, Descriptive Geometry, Technical Graphics and Design, (GTD' 03), Braşov, pp: 353-358.

Petrescu, F. and R. Petrescu, 2005a. The cam design for a better efficiency. Proceedings of the International Conference on Engineering Graphics and Design, (EGD' 05), Bucharest, pp: 245-248.

Petrescu, F. and R. Petrescu, 2005b. Contributions at the dynamics of cams. Proceedings of the 9th IFToMM International Symposium on Theory of Machines and Mechanisms, (TMM' 05), Bucharest, Romania, pp: 123-128.

Petrescu, F. and R. Petrescu, 2005c. Determining the dynamic efficiency of cams. Proceedings of the 9th IFToMM International Symposium on Theory of Machines and Mechanisms (TMM' 05), Bucharest, Romania, pp: 129-134.

Petrescu, F. and R. Petrescu, 2005d. An original internal combustion engine. Proceedings of the 9th IFToMM International Symposium on Theory of Machines and Mechanisms, (TMM' 05), Bucharest, Romania, pp: 135-140.

Petrescu, F. and R. Petrescu, 2005e. Determining the mechanical efficiency of Otto engine's mechanism. Proceedings of the 9th IFToMM International Symposium on Theory of Machines and Mechanisms, (TMM 05), Bucharest, Romania, pp: 141-146.
Petrescu, F.I. and R.V. Petrescu, 2011. Mechanical Systems, Serial and Parallel (Romanian). 1st Edn., LULU Publisher, London, UK, pp: 124.

Petrescu, F.I. and R.V. Petrescu, 2012a. Kinematics of the planar quadrilateral mechanism. ENGEVISTA, 14: 345-348.

Petrescu, F.I. and R.V. Petrescu, 2012b. MecatronicaSisteme Seriale si Paralele. 1st Edn., Create Space Publisher, USA, pp: 128.

Petrescu, F.I. and R.V. Petrescu, 2013a. Cinematics of the 3R dyad. ENGEVISTA, 15: 118-124.

Petrescu, F.I. and R.V. Petrescu, 2013b. Forces and efficiency of cams. Int. Rev. Mech. Eng.

Petrescu, F.I. and R.V. Petrescu, 2016a. Parallel moving mechanical systems kinematics. ENGEVISTA, 18: 455-491.

Petrescu, F.I. and R.V. Petrescu, 2016b. Direct and inverse kinematics to the anthropomorphic robots. ENGEVISTA, 18: 109-124.

Petrescu, F.I. and R.V. Petrescu, 2016c. Dynamic cinematic to a structure 2R. Revista Geintec-Gestao Inovacao E Tecnol., 6: 3143-3154.

Petrescu, R.V., R. Aversa, A. Apicella and F.I. Petrescu, 2016. Future medicine services robotics. Am. J. Eng. Applied Sci., 9: 1062-1087. DOI: 10.3844 /ajeassp.2016.1062.1087

Petrescu, F.I., B. Grecu, A. Comanescu and R.V. Petrescu, 2009. Some mechanical design elements. Proceeding of the International Conference on Computational Mechanics and Virtual Engineering, (MVE' 09), Braşov, pp: 520-525.

Petrescu, F.I., 2011. Teoria Mecanismelor si a Masinilor: Curs Si Aplicatii. 1st Edn., CreateSpace Independent Publishing Platform, ISBN-10: 1468015826. pp: 432.

Petrescu, F.I.T., 2015a. Geometrical synthesis of the distribution mechanisms. Am. J. Eng. Applied Sci., 8: 63-81. DOI: 10.3844/ajeassp.2015.63.81

Petrescu, F.I.T., 2015b. Machine motion equations at the internal combustion heat engines. Am. J. Eng. Applied Sci., 8: 127-137. DOI: 10.3844/ajeassp.2015.127.137

Petrescu, R.V., R. Aversa, B. Akash, R. Bucinell and J. Corchado et al., 2017a. Yield at thermal engines internal combustion. Am. J. Eng. Applied Sci., 10: 243-251. DOI: 10.3844/ajeassp.2017.243.251

Petrescu, R.V., R. Aversa, B. Akash, B. Ronald and J. Corchado et al., 2017b. Velocities and accelerations at the 3R mechatronic systems. Am. J. Eng. Applied Sci., 10: 252-263.

DOI: 10.3844/ajeassp.2017.252.263

Petrescu, R.V., R. Aversa, B. Akash, R. Bucinell and J. Corchado et al., 2017c. Anthropomorphic solid structures n-r kinematics. Am. J. Eng. Applied Sci., 10: 279-291. DOI: 10.3844/ajeassp.2017.279.291 
Petrescu, R.V., R. Aversa, B. Akash, R. Bucinell and J. Corchado et al., 2017d. Inverse kinematics at the anthropomorphic robots, by a trigonometric method. Am. J. Eng. Applied Sci., 10: 394-411. DOI: 10.3844/ajeassp.2017.394.411

Petrescu, R.V., R. Aversa, B. Akash, R. Bucinell and J. Corchado et al., 2017e. Forces at internal combustion engines. Am. J. Eng. Applied Sci., 10: 382-393. DOI: 10.3844/ajeassp.2017.382.393

Petrescu, R.V., R. Aversa, B. Akash, R. Bucinell and J. Corchado et al., 2017f. Gears-part I. Am. J. Eng. Applied Sci., 10: 457-472. DOI: 10.3844/ajeassp.2017.457.472

Petrescu, R.V., R. Aversa, B. Akash, R. Bucinell and J. Corchado et al., 2017g. Gears-part II. Am. J. Eng. Applied Sci., 10: 473-483.

DOI: 10.3844/ajeassp.2017.473.483

Petrescu, R.V., R. Aversa, B. Akash, R. Bucinell and J. Corchado et al., 2017h. Cam-gears forces, velocities, powers and efficiency. Am. J. Eng. Applied Sci., 10: 491-505.

DOI: 10.3844/ajeassp.2017.491.505

Petrescu, R.V., R. Aversa, B. Akash, R. Bucinell and J. Corchado et al., 2017i. Dynamics of mechanisms with cams illustrated in the classical distribution. Am. J. Eng. Applied Sci., 10: 551-567. DOI: 10.3844/ajeassp.2017.551.567

Petrescu, R.V., R. Aversa, B. Akash, R. Bucinell and J. Corchado et al., 2017j. Testing by non-destructive control. Am. J. Eng. Applied Sci., 10: 568-583. DOI: 10.3844 /ajeassp.2017.568.583

Petrescu, R.V., R. Aversa, A. Apicella and F.I.T. Petrescu, 2017k. Transportation engineering. Am. J. Eng. Applied Sci., 10: 685-702. DOI: 10.3844/ajeassp.2017.685.702

Petrescu, R.V., R. Aversa, S. Kozaitis, A. Apicella and F.I.T. Petrescu, 20171. The quality of transport and environmental protection, part I. Am. J. Eng. Applied Sci., 10: 738-755.

DOI: 10.3844/ajeassp.2017.738.755

Petrescu, R.V., R. Aversa, B. Akash, R. Bucinell and J. Corchado et al., $2017 \mathrm{~m}$. Modern propulsions for aerospace-a review. J. Aircraft Spacecraft Technol., 1: 1-8. DOI: 10.3844/jastsp.2017.1.8

Petrescu, R.V., R. Aversa, B. Akash, R. Bucinell and J. Corchado et al., 2017n. Modern propulsions for aerospace-part II. J. Aircraft Spacecraft Technol., 1: 9-17. DOI: 10.3844/jastsp.2017.9.17

Petrescu, R.V., R. Aversa, B. Akash, R. Bucinell and J. Corchado et al., 2017o. History of aviation-a short review. J. Aircraft Spacecraft Technol., 1: 30-49. DOI: 10.3844 jastsp.2017.30.49
Petrescu, R.V., R. Aversa, B. Akash, R. Bucinell and J. Corchado et al., 2017p. Lockheed martin-a short review. J. Aircraft Spacecraft Technol., 1: 50-68. DOI: 10.3844 /jastsp.2017.50.68

Petrescu, R.V., R. Aversa, B. Akash, J. Corchado and F. Berto et al., 2017q. Our universe. J. Aircraft Spacecraft Technol., 1: 69-79.

DOI: 10.3844 jastsp.2017.69.79

Petrescu, R.V., R. Aversa, B. Akash, J. Corchado and F. Berto et al., 2017r. What is a UFO? J. Aircraft Spacecraft Technol., 1: 80-90. DOI: 10.3844 jastsp.2017.80.90

Petrescu, R.V., R. Aversa, B. Akash, J. Corchado and F. Berto et al., 2017s. About bell helicopter FCX-001 concept aircraft-a short review. J. Aircraft Spacecraft Technol., 1: 91-96. DOI: $10.3844 /$ jastsp.2017.91.96

Petrescu, R.V., R. Aversa, B. Akash, J. Corchado and F. Berto et al., 2017t. Home at airbus. J. Aircraft Spacecraft Technol., 1: 97-118. DOI: $10.3844 /$ jastsp.2017.97.118

Petrescu, R.V., R. Aversa, B. Akash, J. Corchado and F. Berto et al., 2017u. Airlander. J. Aircraft Spacecraft Technol., 1: 119-148. DOI: 10.3844/jastsp.2017.119.148

Petrescu, R.V., R. Aversa, B. Akash, J. Corchado and F. Berto et al., 2017v. When boeing is dreaming-a review. J. Aircraft Spacecraft Technol., 1: 149-161. DOI: 10.3844 /jastsp.2017.149.161

Petrescu, R.V., R. Aversa, B. Akash, J. Corchado and F. Berto et al., 2017w. About Northrop Grumman. J. Aircraft Spacecraft Technol., 1: 162-185. DOI: $10.3844 /$ jastsp.2017.162.185

Petrescu, R.V., R. Aversa, B. Akash, J. Corchado and F. Berto et al., 2017x. Some special aircraft. J. Aircraft Spacecraft Technol., 1: 186-203. DOI: 10.3844 /jastsp.2017.186.203

Petrescu, R.V., R. Aversa, B. Akash, J. Corchado and F. Berto et al., 2017y. About helicopters. J. Aircraft Spacecraft Technol., 1: 204-223. DOI: 10.3844 /jastsp.2017.204.223

Petrescu, R.V., R. Aversa, B. Akash, F. Berto and A. Apicella et al., 2017z. The modern flight. J. Aircraft Spacecraft Technol., 1: 224-233. DOI: $10.3844 /$ jastsp.2017.224.233

Petrescu, R.V., R. Aversa, B. Akash, F. Berto and A. Apicella et al., 2017aa. Sustainable energy for aerospace vessels. J. Aircraft Spacecraft Technol., 1: 234-240. DOI: 10.3844/jastsp.2017.234.240

Petrescu, R.V., R. Aversa, B. Akash, F. Berto and A. Apicella et al., 2017ab. Unmanned helicopters. J. Aircraft Spacecraft Technol., 1: 241-248. DOI: $10.3844 /$ jastsp.2017.241.248 
Petrescu, R.V., R. Aversa, B. Akash, F. Berto and A. Apicella et al., 2017ac. Project HARP. J. Aircraft Spacecraft Technol., 1: 249-257. DOI: 10.3844/jastsp.2017.249.257

Petrescu, R.V., R. Aversa, B. Akash, F. Berto and A. Apicella et al., 2017ad. Presentation of romanian engineers who contributed to the development of global aeronautics-part I. J. Aircraft Spacecraft Technol., 1: 258-271.

DOI: 10.3844 /jastsp.2017.258.271
Petrescu, R.V., R. Aversa, B. Akash, F. Berto and A. Apicella et al., 2017ae. A first-class ticket to the planet mars, please. J. Aircraft Spacecraft Technol., 1: 272-281. DOI: 10.3844/jastsp.2017.272.281 